\title{
La huella de Juan XXIII en la Constitución pastoral Gaudium et spes
}

\author{
Ildefonso Camacho Laraña S.I. ${ }^{1}$
}

Resumen: El discurso de apertura del Concilio Vaticano II, Gaudet mater Ecclesia, es la primera clave que propone el autor para captar la relación profunda de Gaudium et spes y el magisterio de Juan XXIII. Las claves de aquel discurso, distinción de la fe y la forma de expresarla, la misericordia frente a la denuncia de los profetas de calamidades, los signos de los tiempos y la pastoralidad conciliar. La parte central el estudio se refiere al influjo de los dos grandes documentos sociales de Juan XXIII, Mater et magistra (1961) y Pacem in terris (1963) en el Concilio y en concreto en la Gaudium et spes, a la hora de esbozar una nueva relación entre Iglesia y sociedad. Por eso el autor afirma que esta constitución conciliar es "la mejor expresión" de que Juan XXIII quiso que fuera el concilio. En la asimilación de las novedades de Gaudium et spes tuvo un influjo determinante Pablo VI, obviamente. El estudio termina esbozando dos líneas de fuerza: la dialéctica de fondo establecida entre tradición y renovación, lo que lleva a afirmar que Gaudium et spes no fue un término de llegada sino un punto de partida.

Palabras clave: aggiornamento, depósito de la fe, Gaudet mater Ecclesia, Gaudium et spes, pastoralidad, relación Iglesia y sociedad, signos de los tiempos.

\section{The imprint of John XXIII in the Pastoral Constitution Gaudium et spes}

\begin{abstract}
Following the custom of our journal, analyze and evaluate the economic policies of Governments which end a legislature, this editorial is about the stage of Rajoy's
\end{abstract}

\section{L'empreinte de Jean XXIII dans la Constitution pastorale Gaudium et spes}

Résumé: Le discours d'ouverture du second concile du Vatican, Gaudet Mater Ecclesia, est la première clé proposée par l'auteur de saisir la relation profonde de Gaudium

'Facultad de Teología de Granada. icamacho@probesi.org 
Government from 2011 to 2015 . There is a broad consensus on the obligation of an austerity policy imposed by the European framework in 2011 to avoid intervention. In the Spanish and European context of that year, the Government had no other way out than the budgetary stability with the containment of public expenditure. From the event that economic policy is primarily political, although one of their complex forms, and that all economic policy must take into account constraints of the immediate context that exerts more influence in that, our analysis of this attempt to explain the behavior of public officials, essentially the Government during that period.

Keywords:aggiornamento, deposit offaith, Gaudet Mater Ecclesia , Gaudium et spes, pastorality, relationship Church and society, signs of the times. et spes et l'enseignement de Jean XXIII. Les clés de ce discours, la distinction de la foi et de la façon de l'exprimer, la plainte contre les prophètes de malheur et l'éloge de la miséricorde, les signes des temps et la pastoralité conciliaire. La partie centrale de l'étude concerne l'influence des deux grands documents sociaux de Jean XXIII, Mater et Magistra (1961) et Pacem in Terris (1963) au sein du Concile et en particulier sur la Gaudium et spes, quand décrivant une nouvelle relation entre l'Église et la société. Ainsi, l'auteur affirme que cette constitution conciliaire est "la meilleure expression" de ce que Jean XXIII voulait que ce soit le concile. Dans l'assimilation des nouveautés de Gaudium et spes eu évidemment une influence décisive Paul VI. L'étude se termine en décrivant deux lignes de force: I'arrièreplan dialectique établi entre tradition et renouveau, conduisant à dire que Gaudium et spes n'était pas un terme d'arrivée, mais un point de départ.

Mots clé: aggiornamento, dépôt de la foi, Gaudet Mater Ecclesia, Gaudium et spes, pastoralité, relation Église et société, signes des temps.

Recibido: 19 de julio de 2015. 


\section{Introducción: el discurso de Juan XXIII en la inauguración del Concilio y su reflejo en Gaudium et spes}

Que el concilio Vaticano II no hubiera sido posible sin Juan XXIII es hoy comúnmente aceptado, aunque no por todos con el mismo entusiasmo. Pero cabría añadir algo más: tampoco Gaudium et spes hubiera sido lo mismo sin Juan XXIII, sus actitudes y sus dos encíclicas sociales, Mater et magistra y Pacem in terris. ¿Cuál es, pues, la huella de Juan XXIII en la constitución pastoral del Concilio?

Es cierto que Gaudium et spes (GS) comenzó a gestarse cuando ya Juan XXIII había muerto, pero su espíritu y su inspiración habían calado profundamente en el Concilio, quizás porque él había sabido interpretar y encarnar muchas demandas existentes en la lglesia, que el centralismo de la época anterior no había dejado aflorar.

La huella de Juan XXIII en GS puede esquematizarse en tres niveles, que vamos a desarrollar en estas páginas.

Se dice que el papa Juan dedicó mucho tiempo a preparar esta intervención. Y es explicable, dada la trascendencia del momento y lo que se presumía iba a estar en juego en el día a día del Concilio después de las tensiones que se habían manifestado en toda la etapa preparatoria. Nos interesa detenernos en este discurso de Juan XXIII (Gaudet Mater Ecclesia), que Peter Hebblethwaite considera "resumía su vida entera" ${ }^{\prime 2}$, porque sus orientaciones encontraron un eco indudable en GS (especialmente en la Exposición Preliminar y en la Parte I).

Para captar mejor lo esencial de su contenido reproduciremos tres pasajes del mismo donde se expresan sus tres ideas más destacadas ${ }^{3}$. Mostraremos además cómo se reflejan en GS.

\section{I.I. Denuncia de los profetas de calamidades}

En las palabras que siguen se nos descubren las dificultades que habría tenido que afrontar el papa en la preparación del Concilio. Su tono no es el acostumbrado en ocasiones tan solemnes como la inauguración de un concilio ecuménico. ¿Cómo resonarían en sus oyentes? Dijo Juan XXIII:

${ }^{2}$ HeBblethwaite 2000, 550.

${ }^{3}$ Cf. Alberigo 1981; Hebblethwaite 1983. 
En el cotidiano ejercicio de Nuestro pastoral ministerio, de cuando en cuando llegan a Nuestros oídos, hiriéndolos, ciertas insinuaciones de algunas personas que, aun en su celo ardiente, carecen del sentido de la discreción y de la medida. Ellas no ven en los tiempos modernos sino prevaricación y ruina; van diciendo que nuestra época, comparada con las pasadas, ha ido empeorando; y se comportan como si nada hubieran aprendido de la historia, que sigue siendo maestra de la vida, y como si en tiempo de los precedentes Concilios Ecuménicos todo hubiese procedido con un triunfo absoluto de la doctrina y de la vida cristiana, y de la justa libertad de la Iglesia.

Nos parece justo disentir de tales profetas de calamidades, avezados a anunciar siempre infaustos acontecimientos, como si el fin de los tiempos estuviese inminente.

En contraste con estos profetas de calamidades, Juan XXIII muestra siempre una visión más benévola de la realidad, que le permite destacar, sin caer en ingenuidades, lo que de positivo hay en los tiempos recientes. Esta actitud de valoración positiva es la que domina también en la "Exposición preliminar" de GS cuando se describe la "Situación del hombre en el mundo de hoy". En ella se destacan los cambios acelerados en los últimos tiempos gracias al progreso reciente favorecido por la inteligencia humana, al desarrollo de la ciencia y de la técnica, a la industrialización y urbanización. Estos cambios no carecen de ambigüedades (las desigualdades crecientes, entre ellas). No faltan los desequilibrios, pero al mismo tiempo las aspiraciones de la humanidad se hacen más universales. En el terreno religioso, el espíritu crítico ayuda a una purificación de la religión y postula una adhesión verdaderamente personal a la fe (GS 7).

En resumen, el mundo moderno aparece a la vez poderoso y débil, capaz de lo mejor y de lo peor, pues tiene abierto el camino para optar entre la libertad o la esclavitud, entre el progreso o el retroceso, entre la fraternidad o el odio (GS 9).

\section{I.2. Distinción entre el depósito de la fe y la forma de expresarlo}

Se tocaba aquí una cuestión a la que se era especialmente sensible en los ambientes vaticanos. Oigamos las palabras de Juan XXIII:

La tarea principal de este Concilio no es, por lo tanto, la discusión de este o aquel tema de la doctrina fundamental de la Iglesia, repitiendo difusamente la enseñanza de los Padres y Teólogos antiguos y modernos, que os es muy bien conocida y con la que estáis tan familiarizados.

Para eso no era necesario un Concilio (...). El espíritu cristiano y católico del mundo entero espera que se dé un paso adelante hacia una penetración doctrinal y una formación de las conciencias que esté en correspondencia más perfecta con la fidelidad a la auténtica doctrina, estudiando ésta y exponiéndola a través de las formas de investigación y de las fórmulas literarias del pensamiento moderno. Una cosa es la substancia de la antigua 
doctrina, del "depositum fidei", y otra la manera de formular su expresión; y de ello ha de tenerse gran cuenta -con paciencia, si necesario fuese- ateniéndose a las normas y exigencias de un magisterio de carácter predominantemente pastoral.

Evidentemente Juan XXIII estaba pensando en un concilio muy distinto al que tenían en la cabeza muchos de los que intervinieron directamente en la preparación. Él era muy consciente de que se estaba en un tiempo de cambios rápidos y eso exigía mirar más a la realidad que a la doctrina. Nos encontramos al final de estas líneas con el término pastoral, al que recurría con frecuencia Juan XXIII para indicar la orientación que quería para el Concilio. Hay aquí una nueva vivencia de la Iglesia, que se coloca en una actitud de peregrina junto a la humanidad (compartiendo gozos y esperanzas, GS 1), que se siente impulsada a escrutar los signos de los tiempos (GS 4) y que reconoce no poseer respuestas acabadas para todos los problemas que se plantean.

Para calibrar la importancia de este enfoque es preciso recordar que el término "pastoral", que aquí se contrapone a "doctrinal", suscitó no poca inquietud en el entorno del papa. Un reflejo de ello es el hecho de que el texto que hemos reproducido fue matizado en la edición oficial que pasó a las actas para destacar más la irrenunciable referencia a la doctrina ${ }^{4}$. Volveremos más abajo sobre esta cuestión.

\section{I.3. La medicina de la misericordia}

Juan XXIII quiere que ésta sea otra novedad de "su" concilio a diferencia de todos los anteriores: que los errores se repriman con la medicina de la misericordia y no con la de la severidad. Con sus palabras:

Siempre la Iglesia se opuso a estos errores. Frecuentemente los condenó con la mayor severidad. En nuestro tiempo, sin embargo, la Esposa de Cristo prefiere usar la medicina de la misericordia más que la de la severidad. Ella quiere venir al encuentro de las necesidades actuales, mostrando la validez de su doctrina más bien que renovando condenas. No es que falten doctrinas falaces, opiniones y conceptos peligrosos, que precisa prevenir y disipar; pero se hallan tan en evidente contradicción con la recta norma de la honestidad, y han dado frutos tan perniciosos, que ya los hombres, aun por sí solos, están propensos a condenarlos...

${ }^{4}$ Cuando se menciona la doctrina se añade este inciso: doctrina, cierta e inmutable, a la que hay que prestar una fiel adhesión. Y luego se intercalan en la versión oficial latina estas palabras que van subrayadas: Una cosa es la substancia de la antigua doctrina, del "depositum fidei", o verdades, en que se contiene nuestra venerable doctrina, y otra la manera de formular su expresión, pero manteniendo el mismo sentido y la misma acepción (...). Las palabras subrayadas no estaban en el discurso que Juan XXIII pronunció, tampoco figuran en la versión castellana que se puede consultar en la página web de la Santa Sede, pero sí están en las otras tres versiones que ofrece la misma web (la latina oficial, la italiana y la portuguesa). 
De nuevo aquí aparece este sentido positivo: más que condenar (al error o al que yerra), mostrar el valor de la doctrina (la verdad). También aquí se encontró con una resistencia que tenía su apoyo en la praxis de todos los concilios anteriores, cuyo centro fue tantas veces el corregir y condenar los errores. Durante el Vaticano II no faltaron presiones para que se condenaran determinadas posturas. Dos particularmente: el ateísmo y, sobre todo, su concreción en el marxismo. Y fue a propósito de GS cuando esta demanda se hizo más fuerte por parte de un grupo no despreciable de padres. No lograron su intento. Y el tratamiento del ateísmo en la Constitución pastoral es bien significativo (GS 19-21). Su marco es el reconocimiento de la dignidad de la persona humana y el respeto debido a la misma, que es como el "leitmotiv" sobre todo en el capítulo 1 de la parte I de GS, pero también el relieve que se da a la conciencia y a la libertad. En los días en que este texto estaba discutiéndose en el aula, estaba también debatiéndose otro de los temas más difíciles en el Concilio, y que no carecía de relación con éste: el reconocimiento del derecho a la libertad religiosa.

\section{La encíclicas sociales de Juan XXIII y su reflejo en Gaudium et spes}

El objeto de esta parte es analizar la huella de las dos encíclicas sociales en la Constitución pastoral. Pero ello exige dos observaciones previas. Ante todo, la sorpresa porque, en un pontificado tan breve, Juan XXIII fuera capaz de producir dos documentos de este rango, cifra inusual si se compara con los papas que le precedieron. Lo segundo es más importante: destacar la novedad que estos dos textos representan para la línea dominante en la Doctrina Social de la Iglesia hasta Pío XII. Cabe adelantar que la doctrina social de Juan XXIII abrió el camino a muchos contenidos que luego el Concilio desarrolló.

Con estas premisas veamos cada una de las dos encíclicas por separado.

\section{I. La doctrina social y económica de Mater et magistra (MM) y su eco en Gaudium et spes}

Para ambientar este punto conviene señalar que con Juan XXIII cambia la actitud de la Santa Sede en relación con el conflicto ideológico que marca el siglo XX tal como se refleja en el escenario político italiano. Pío XII había mantenido una postura de oposición abierta al comunismo, recurriendo para ello a la Democracia Cristiana 
italiana y a la Acción Católica. Pensaba que de este modo podría salvar a Italia de la amenaza comunista. Con Aldo Moro, sin embargo, se había iniciado una actitud de apertura a la izquierda, que llevaría al líder democristiano en 1960 a aliarse con el Partido Socialista. Juan XXIII tenía la clara convicción de que no debía intervenir, y así se lo hizo saber al Primer Ministro, Amintore Fanfani, en su encuentro de 11 de abril de 1961. Esta nueva situación produjo inquietud en los ambientes vaticanos. Personas como los cardenales Ottaviani, Siri y Tardini difícilmente aceptaban esta "apertura a sinistra", en gran parte por miedo al avance del comunismo ${ }^{5}$. Y estas circunstancias deben ser tenidas en cuenta para calibrar mejor lo que supuso la publicación de $\mathrm{MM}^{6}$.

A la hora de sintetizar algunos aspectos significativos de $M M$, tanto por su novedad como por el influjo que pudieron tener en GS, nos gustaría fijarnos en cuatro, que pasamos a recoger.

1) La aceptación no polémica de un sistema mixto de organización socioeconómica. La Doctrina Social de la Iglesia nació en el contexto de un agudo enfrentamiento entre las dos grandes ideologías modernas, el liberalismo y el socialismo-marxismo: ambas se plasman respectivamente en el Estado liberal y el capitalismo liberal, por una parte, y en el modelo comunista instaurado tras la revolución rusa en 1917 y en las sucesivas fracturas que se dan en el movimiento comunista a lo largo del siglo XX. La apuesta por el derecho de propiedad privada había sido un reflejo de esto, al tiempo que se marcaba un claro distanciamiento, por una parte de la ideología comunista, pero por otra también de la liberal y de su tendencia a concebir las libertades humanas (las "libertades modernas") prácticamente sin limitación en su ejercicio.

\footnotetext{
${ }^{5}$ Las dificultades de Juan XXIII con el cardenal Ottaviani fueron de diversa índole. Entre ellas destaca una institución que puso éste en marcha (el "Instituto San Pío V") para la defensa y el fortalecimiento de los valores cristianos, que en realidad daba cobertura a actividades políticas contra el centroizquierda italiano que en nada agradaban al papa Juan. El propio papa, en sus notas del 23 de febrero de 1962, habla del cardenal como "questa grande croce del mio humile servizio di servus servorum Dei" (JUAN XXIII 2007, 352.
}

${ }^{\circ}$ Cf. Hebbletwhaite 2000, 457-466. En la pág. 465 se informa que Juan XXIII consultó para escribir este documento a los cardenales Richaud (Burdeos) y König (Viena), a Mr. Cardijn y a Pietro Pavan. VILLAIN 196, 17-18, completó desde muy pronto estos datos siguiendo una información de la Agencia France Press: cita los nombres de Mr. Pavan y Mr, Ferrari-Toniolo, especialistas en cuestiones sociales, junto con Mr. Parente, teólogo y asesor del Santo Oficio. Y recoge otra información según la cual el primer borrador fue encomendado por Juan XXIII a cinco jesuitas (tres de la Universidad Gregoriana de Roma y dos de Action Populaire de París); a partir de ese primer esbozo la redacción del texto fue encomendada a Mr. Parente, con un equipo de varios expertos en cuestiones sociales; finalmente el texto fue consultado a una veintena de obispos. 
Juan XXIII no se implica en esta confrontación más ideológica y busca fórmulas más equilibradas. Y así afirma la libre iniciativa privada de los individuos como base de la organización socioeconómica, pero añadiendo inmediatamente el necesario complemento de la intervención de los poderes públicos, la cual "fomenta, estimula, ordena, suple y completa" la acción de los particulares de acuerdo con el principio de subsidiariedad (MM 51-53). Así ha dejado claro que opta por un sistema mixto, mostrando a continuación cómo "cuando falta la actividad de la iniciativa particular, surge la tiranía política", pero también cómo cuando "falta totalmente, o es defectuosa, la debida intervención del Estado, los pueblos caen inmediatamente en desórdenes irreparables y surgen al punto los abusos del débil por parte del fuerte moralmente despreocupado" (MM 57-48). Sin entrar en grandes polémicas las referencias son inequívocas.

GS se sitúa ya en esta estela. Esto le permite denunciar los problemas que se observan tanto en las economías colectivizadas como en las otras: por una parte, ese espíritu economicista que lo invade todo; por otra, las desigualdades crecientes (GS 63c).

2) La socialización como fenómeno propio de nuestro tiempo. El término mismo causó problema entre los que leyeron el borrador de la encíclica, porque "socialización" se relacionaba casi espontáneamente con "socialismo", una palabra muy sospechosa para muchos oídos. En realidad, con la palabra "socialización" se quería aludir al incremento de las relaciones sociales, o sea la progresiva multiplicación de las relaciones de convivencia, con la formación consiguiente de muchas formas de vida y de actividad asociada. Pero muchos la interpretaron como un peligroso acercamiento al socialismo; incluso desde la izquierda fue interpretado así, no de forma desinteresada. Probablemente fue el punto más discutido de la encíclica ${ }^{7}$.

Ese contexto polémico explica quizás que el texto oficial latino nunca emplee la citada palabra y prefiera recurrir a diferentes circunlocuciones. Es el mismo criterio que sigue la versión castellana. Pero es significativo que el texto italiano, que es el original, emplea en todas las ocasiones la palabra "socializzazione": de este modo se puede identificar de forma más clara el fenómeno al que se quiere aludir ${ }^{8}$. Estos titubeos sirven para mostrar cuán cauto se era hasta en el

${ }^{7}$ Los ecos de esta polémica pueden verse en SORGE 1963, que distingue entre el sentido económicopolítico y el social o sociológico del término. Y cita mucha de la abundante bibliografía aparecida en los dos primeros años. Véase también CALVEZ 1962.

${ }^{8} \mathrm{CF}$. CAMACHO 1998, 231-234. Las versiones francesa y portuguesa han seguido a la italiana y emplean 
uso de las palabras, sobre todo cuando éstas podrían tener connotaciones que las relacionaban con fenómenos ambiguos (el caso del socialismo).

Nada de esto encontramos ya en GS, donde el término "socialización" se emplea en el sentido que aparecía en $M M$, incluso empleando el neologismo latino "socializatio". Pero con un matiz diferente: no se piensa tanto en un fenómeno social cuando en una dimensión constitutiva de todo ser humano, la dimensión social ${ }^{9}$.

3) Un nuevo enfoque de los temas clásicos: trabajo y propiedad. Los llamamos "temas clásicos" porque habían sido recurrentes en todos los documentos anteriores, como reflejo de la confrontación entre el capitalismo liberal y la alternativa que representaba el comunismo. Pero se abordaban colocando en primer término la afirmación de la propiedad privada, centro del debate con los movimientos socialistas desde el siglo XIX y exigiendo luego un trato digno para el trabajador (salario justo, condiciones de trabajo, etc.). MM introduce cambios significativos, cuyas novedades pueden sintetizarse en las tres que siguen:

- Se invierte el orden en que ambos temas son tratados: primero, el trabajo, al que se dedica un pasaje bastante extenso (MM 68-103); luego, la propiedad (MM 104-121). Este cambio de orden puede parecer irrelevante, pero supone una mejor jerarquización (la persona humana en el trabajo es anterior a los instrumentos que emplea para producir).

- Al trabajo se dedica un pasaje muy extenso, que lo contempla en su doble faceta de factor de producción (con una renovada reflexión sobre los criterios para una retribución justa) y como actividad humana (lo que implica una atención, que no existía en los documentos sociales precedentes, a la participación del trabajador en los procesos decisionales de la empresa y de las instituciones socioeconómicas de más alcance). Es a este segundo aspecto al que se dedica la parte más extensa de este pasaje (MM 82-103).

respectivamente los términos "socialisation" y "socialização"; no así las alemana e inglesa, que siguen la latina.

${ }^{9}$ Así ocurre claramente en GS 25b, cuando se habla de las muchas asociaciones que nacen en la sociedad como expresión de la índole social de la persona. Las otras citas están en GS 6e (como uno de los cambios sociales más significativos de nuestro mundo), GS 42c (socialización civil y económica como expresión del dinamismo social actual), GS 75c (al hablar de la participación en la vida pública). 
- En el tratamiento de la propiedad, que queda relegada a un segundo lugar, también se observan cambios sintomáticos: se destaca ante todo cómo en la economía moderna sus funciones son diferentes a las tradicionales; pero ello no es óbice para reafirmar que es un derecho natural, de acuerdo con la doctrina tradicional, expresada casi con mayor contundencia que en Rerum novarum; al mismo tiempo, sin embargo, se admite la compatibilidad de la propiedad privada con formas de propiedad pública (cosa que sería impensable en la concepción de la encíclica de León XIII, donde la afirmación de la propiedad privada es excluyente); por fin, hay un reconocimiento muy explícito de la función social de la propiedad. Todos estos elementos configuran una doctrina de la propiedad que pone acentos muy distintos de los dominantes en documentos anteriores.

El capítulo $3^{\circ}$ de GS ("La vida económico-social") recoge y profundiza todos estos cambios. Incorpora el orden de trabajo-capital ya introducido por MM. Pero donde mayor se percibe el avance es en la doctrina sobre la propiedad: aparece ya en primer término el destino universal de los bienes de la tierra, recuperando el enfoque más clásico de la tradición cristiana, que fue olvidado curiosamente en la segunda escolástica, justo cuando más aguda era la polémica con el liberalismo decimonónico ${ }^{10}$. Hay que destacar además cómo la propiedad, o cualquier otra forma de dominio, ocupa ya un lugar claramente subordinado al destino universal, lo que justificaría incluso el recurso a una eventual expropiación de bienes privados ${ }^{11}$.

4) La denuncia de las desigualdades en el mundo. Si toda la mayor parte de MM se mantiene en el marco de los documentos sociales de los papas que precedieron a Juan XXIII, hay en esta encíclica una parte que abre un horizonte nuevo: la de aquellos problemas socioeconómicos que ya no pueden reducirse a las relaciones entre trabajadores y empresarios. Se trata de las desigualdades en diferentes dimensiones: entre los distintos sectores de la economía, entre las zonas de diverso nivel de riqueza en el interior de cada nación y entre países con diferente grado de desarrollo económico y social. Estamos, más que ante una elaboración doctrinal acabada, ante una constatación inquietante y una

\footnotetext{
${ }^{10}$ Sigue siendo esencial la lectura de SOUSBERGHE 1960.

"La evolución de la doctrina sobre la propiedad desde Rerum novarum hasta GS es el ejemplo más elocuente del carácter dinámico de la Doctrina social de la Iglesia, que no puede ser entendida de ninguna manera como un cuerpo cerrado de principios inmutables. Cf. САMACHO 2014.
} 
denuncia. Pero ello supone que desde ahora el centro de atención está en otro lugar: en la realidad de las desigualdades, ya no producidas solo por las relaciones entre capital y trabajo, sino por dinamismos más amplios y complejos. Se va abriendo el horizonte a los grandes problemas del conflicto Norte-Sur.

Esta preocupación por las desigualdades en el mundo era muy aguda en tantos padres conciliares procedentes de países en vías de desarrollo, pero no llegó a quedar reflejada adecuadamente en los documentos que el Concilio aprobó. Es indudable que en éste tuvo más presencia y más peso la problemática propia de los países más desarrollados. Sólo en el capítulo $5^{\circ}$ hay alusiones inequívocas. Su mensaje central es la necesidad de basar la paz sobre la eliminación, no sólo de la guerra, sino de todas las injusticias y desigualdades que están en la raíz de la violencia (GS 83), y eso implica los esfuerzos responsables de cada país pero también la cooperación de los más ricos (GS 85).

En relación con esta nueva conciencia de las desigualdades en el mundo, la aportación más interesante de GS a la doctrina socioeconómica es el colocar el concepto ético de desarrollo como punto de partida de todo el capítulo $3^{\circ}$ de la $2^{a}$ parte: el auténtico desarrollo como desarrollo de todo el hombre y de todos los hombres (GS 64). Desarrollo integral y solidario, podríamos traducir nosotros. En un contexto histórico de cierta euforia desarrollista la propuesta de Concilio es de un especial valor: toma distancia crítica de una forma de entender el desarrollo que lo vincula demasiado con crecimiento económico, al tiempo que cuestiona que de dicho desarrollo no se aprovechen todos por igual y ello esté provocando un incremento de las desigualdades.

\subsection{La doctrina política de Pacem in terris (PT) y su huella en Gaudium et spes}

La segunda encíclica de Juan XXIII supone en algún sentido una solución de continuidad con todo lo que había sido el magisterio social contemporáneo ${ }^{12}$. Desde el siglo XIX éste había insistido en que la paz en nuestras sociedades solo era posible desde una vuelta al cristianismo y sus propuestas -al régimen de cristiandad-; para ello no había otro camino que el de renunciar definitivamente a la tan repetida "genealogía de los errores modernos": Lutero y el libre examen, la revolución francesa y el liberalismo, el socialismo y el comunismo, el nazismo como reacción contra éste último.

${ }^{12}$ Cf. Melloni 1996. 
Juan XXIII parte de una experiencia vital diferente. Experimentó los horrores de la guerra como capellán de un hospital entre 1914 y 1918. Sus veinte años en Oriente (1925-1944: Bulgaria y Turquía) le llevaron a relativizar una visión de la Doctrina Social de la lglesia demasiado acuñada desde la mentalidad occidental y europea. Y en los años de nunciatura en París (1944-1953) se confirma en la idea de que la nostalgia de la cristiandad no vale ya para responder a los problemas del mundo de la posguerra. En este sentido le resultaría insuficiente el borrador sobre el orden social que se había elaborado en la fase preparatoria del Concilio, en el que se volvía sobre las mismas ideas: la paz sólo puede ser resultado de la obediencia a los preceptos evangélicos y a la voz del magisterio de la Iglesia.

En este ambiente se produce la crisis de los misiles soviéticos en Cuba, un momento de fuerte tensión entre Estados Unidos y la Unión Soviética, en que la paz mundial se vio seriamente amenazada. Se dice que fue en aquel momento cuando concibió la encíclica sobre la paz. Su secretario personal, Loris Capovilla, se atrevió incluso a ponerle fecha: fue el 25 de octubre de 1962, cuando el papa trabajaba en la redacción del mensaje que habría de dirigir a Kruchev y a Kennedy ${ }^{13}$. En él no invoca su propia autoridad, sino el grito de la humanidad. El éxito de esta misiva, que contribuyó sin duda a evitar el conflicto abierto, provocó en el papa una cierta conciencia de su responsabilidad en este campo. Y fue en estas circunstancias cuando Pietro Pavan, entonces rector de la Universidad Lateranense, dirigió una carta a Loris Capovilla el 23 de noviembre sugiriendo la conveniencia de una encíclica papal en el campo "socio-político" que marcase líneas de acción claras y seguras, con un estilo positivo, un lenguaje sencillo y un modo de argumentar accesible. Incluso se ofrecía para elaborar un primer borrador ${ }^{14}$. La respuesta del papa tardó poco: Pavan recibió el encargo de redactar el texto, indicándosele además el deseo papal de que fuera la encíclica "de Pascua" ${ }^{15}$.

${ }^{13}$ Cf. Hebblethwaite 2000, 572; con más detalle, Melloni 2010, 26-37.

${ }^{14} \mathrm{El}$ texto de esta carta está reproducido en: MELLONI 2010, 103-104.

${ }^{15}$ El mismo Pavan escribiría más tarde:

A comienzos de 1963, en una conversación confidencial, el papa Juan expresaba la convicción de que su mensaje había contribuido a salvaguardar la paz, y concluía: que eso era un signo de que cuando él hablaba de paz los hombres prestaban atención a lo que decía; era, por consiguiente, oportuno para él, incluso obligatorio, retomar el tema para indicar a la luz de la razón iluminada por la fe, y con un lenguaje sencillo, esencial y accesible al hombre de la calle cual es la auténtica paz y cuáles las vías seguras que conducen a ella. PAVAN 1984, 107.

Recientemente el historiador benedictino Hilari Raguer ha escrito que le oyó al mismo Pavan lo que el papa le dijo al hacerle el encargo: No sabía que tenía tanto poder. Los dos hombres más poderosos del mundo han hecho caso de un telegrama mío. He de poner este poder al servicio de la humanidad. 
Ni siquiera la conciencia de la grave enfermedad que padecía le frenó en la iniciativa ${ }^{16}$, más bien le animó a acelerar su redacción. La encíclica estuvo lista en un tiempo record. El 7 de enero de 1963 Juan XXIII leía el primer borrador, que lo encontró "muy bien ensamblado y bien hecho" ${ }^{17}$. Siguieron las observaciones de dos teólogos consultados (el dominico Luigi Ciappi y el jesuita Georges Jarlot); para marzo ya estuvo lista la traducción latina que Juan XXIII estudió detenidamente el 17 de ese mismo mes; la firma solemne se produjo el 11 de abril (Jueves Santo) ante las cámaras de la televisión italiana. Juan XXIII moriría unas semanas después, el 3 de junio de ese año. Es lógico que PT fuese considerada como el testamento del papa Juan.

En la fase de elaboración se fue imponiendo con matices la intención y el enfoque originarios de Pavan: no quería sin más reproducir la doctrina de los pontífices anteriores; pretendía un modo nuevo, más atento a los signos de los tiempos para responder a los desafíos del momento. Los miembros de la curia vaticana (todos del entorno de la Secretaría de Estado) presionaron para que el texto no chocara con la doctrina anterior, lo que explica las citas frecuentes de los papas del siglo $X X^{18}$.

No es posible analizar todo su contenido. Pero sí conviene recordar su esquema en cinco partes: las cuatro primeras estudian sistemáticamente los cuatro niveles en que actuar para construir la paz (relaciones entre ciudadanos; relaciones de los ciudadanos con las autoridades públicas del Estado; relaciones entre los Estados; comunidad mundial de todos los pueblos), mientras que la quinta tiene un carácter especial y estudia el papel de los cristianos en esa tarea de la paz. Con este esquema de fondo nos limitamos a comentar los puntos más sobresalientes y su reflejo en la constitución pastoral del Concilio.

He decidido escribir una encíclica sobre la paz. Cf. H. RAGUER, "De Roncalli a Bergoglio: la otra diplomacia vaticana", Religión Digital (15 marzo 2015).

${ }^{16}$ El 23 de septiembre de 1962 las pruebas médicas dieron un diagnóstico preocupante (cáncer de estómago), que fue comunicado a Loris Capovilla, el cual lo trasmitió al papa. El 29 de noviembre de ese año el diario Osservatore Romano revela que el papa tiene que suspender audiencias como consecuencia de algunos "desgarros gástricos". Tomamos los datos de HebBletHWAITE 2000, 544 y 586.

${ }^{17}$ Anotación en su agenda, correspondiente a ese día: JUAN XXIII 2007, 482.

${ }^{18} \mathrm{Cf}$. MeLLoni 2010, 38-82. Los textos con las observaciones de Ciappi y Jarlot, así como otros documentos de la fase preparatoria están también recogidos en este libro, pp.104-118. Otros testimonios afirman que Pavan fue "el único redactor de la encíclica", el cual había rechazado todas correcciones que se le propusieron, incluso por quienes eran más amigos suyos: Cf. CONGAR 2002, 367. 
1) Los signos de los tiempos. Los cuatro primeros capítulos (no el quinto) terminan con un apartado en que se enumeran los signos de los tiempos más significativos. Antes de presentar la lista de los mencionados en los distintos capítulos, conviene advertir que la expresión ha desaparecido en la versión castellana e incluso en el texto latino oficial $^{19}$, a pesar de aparecer en el texto original, que es italiano ${ }^{20}$. Por otra parte, falta una definición del concepto y tampoco se ofrece un tratamiento muy elaborado de los mismos. Vale, sin embargo, la intuición de base: que la atención a ellos es decisiva para construir la paz en el mundo. Por eso merece la pena tener una visión de conjunto de los signos de los tiempos mencionados al final de cada uno de los capítulos. Hela aquí.

- En el capítulo 1 ("Ordenación de las relaciones civiles") introduce tres: el progreso económico-social del mundo laboral, la presencia de la mujer en la vida pública, la independencia de todos los pueblos (ya no hay dominadores y dominados) (PT 39-42).

- En el capítulo 2 ("Ordenación de las relaciones políticas") enumera otros tres: los derechos fundamentales están en la base de todas las constituciones políticas, las relaciones en la comunidad política se fijan en términos jurídicos, las relaciones entre ciudadanos y poderes públicos se establecen en términos de derechos y deberes ${ }^{21}$ (PT 75-77).

- En el capítulo 3 ("Ordenación de las relaciones internacionales") sólo se señala uno: la convicción de que las diferencias hay que resolverlas, no con el recurso a las armas sino mediante la negociación y el convenio (PT 126-129).

\footnotetext{
${ }^{19}$ La expresión se mantiene en el texto francés (Signes des temps), en el alemán (Zeichen der Zeit) y en portugués (Sinais dos tempos), pero no en el inglés ni en castellano; tampoco en el latino, que ha eliminado todos los epígrafes, hasta los títulos de los capítulos (al menos en la web de la Santa Sede). No es una cuestión banal: ya sabemos que Pavan había querido un método nuevo, para el que los signos de los tiempos eran clave. De ahí que la supresión de dicha expresión en la versión oficial pueda interpretarse como una forma de quitar relieve a la propuesta de Pavan.
}

${ }^{20}$ Aunque la encíclica se escribió en italiano, desde el momento que se hizo la traducción latina (marzo 1963), que daría lugar al texto oficial, las correcciones se hicieron sobre este último. Posteriormente se incorporaron al texto italiano. Esta circunstancia obliga a proceder con cautelan a la hora de considerar el texto italiano como el original a todos los efectos. Cf. MELLONI 2010, 79.

${ }^{21}$ Llama la atención que la versión castellana formula estos tres puntos en términos de imperativos éticos (no sólo se utiliza en los tres casos la expresión "se requiere", sino que el apartado lleva como epígrafe "Exigencias de la época", en vez de "Signos de los tiempos". Es un indicio más de que los responsables de la traducción a nuestra lengua no captaron del todo el sentido que se daba al término en la encíclica. 
- Enel capítulo 4("Ordenación de las relaciones mundiales") se mencionan dos: la constitución de la Organización de las Naciones Unidas y su realización más importante, la Declaración de los Derechos Humanos (PT 142-145).

2) Dignidad de la persona y derechos humanos, base para la paz. Ésta es, sin duda, la principal aportación de PT: fundamentar la paz, no en la obediencia a la doctrina cristiana, sino en el recurso a una filosofía natural, aunque quede claramente afirmado que ésta encuentra su justificación auténtica en el designio de Dios.

En toda convivencia humana bien ordenada y provechosa hay que establecer como fundamento el principio de que todo hombre es persona, esto es, naturaleza dotada de inteligencia y de libre albedrío, y que, por tanto, el hombre tiene por sí mismo derechos y deberes, que dimanan inmediatamente y al mismo tiempo de su propia naturaleza. Estos derechos y deberes son, por ello, universales e inviolables y no pueden renunciarse por ningún concepto (PT 9).

Como decimos, esta fundamentación natural no es óbice para añadir la perspectiva cristiana, que la refuerza y enriquece:

Si, por otra parte, consideramos la dignidad de la persona humana a la luz de las verdades reveladas por Dios, hemos de valorar necesariamente en mayor grado aún esta dignidad, ya que los hombres han sido redimidos con la sangre de Jesucristo, hechos hijos y amigos de Dios por la gracia sobrenatural y herederos de la gloria eterna (PT 10).

Esta "normalización" del discurso sobre los derechos humanos supone un giro revelador, que hay que valorar en contraste con la postura que había mantenido Pío XII. Si los derechos humanos fueron el horizonte al que recurrió la Organización de las Naciones Unidas para poner las bases de la paz en el mundo desde una perspectiva no confesional, Pío XII siempre se mostró reticente a mencionar a la ONU y a la Declaración Universal. Juan XXIII no sólo hace una referencia encomiástica a la citada organización sino que basa toda la doctrina de PT en los derechos humanos, reconciliándose así con una tradición que la Iglesia siempre miró oficialmente con reservas por el marco en que se desarrolló (la revolución de 1789 y el pensamiento moderno liberal).

Es más, este deseo de reconciliación justifica probablemente el interés de PT por mostrar que todos los derechos que se van enumerando tienen precedentes en documentos anteriores de la Iglesia, documentos que se van citando a pie de página a propósito de cada derecho que se enuncia ${ }^{22}$.

22 Los derechos son enumerados en PT 11-29, números a los que corresponden las notas 8 a 24. 
Esta normalización es ampliamente asumida por GS, donde no hay ya rastros de aquellas reservas tradicionales. Llama la atención, con todo, que PT no se cite en GS sino en el capítulo $2^{\circ}$ de la primera parte (dimensión social de la persona humana), y no en el $1^{\circ}$ (sobre la dignidad de la persona humana).

3) La concepción del Estado y la apuesta por la democracia. PT supera la oposición en que se había visto encerrado el magisterio anterior entre Estado confesional y Estado laico ${ }^{23}$. Texto que expresaba nítidamente esta contraposición fue la encíclica Immortale Dei de León XIII, publicada en 1885 sobre la constitución cristiana del Estado. Es ilustrativo este pasaje que explica cómo el mundo occidental se ha ido apartando del verdadero camino:

Sin embargo, el pernicioso y deplorable afán de novedades promovido en el siglo XVI, después de furbar primeramente la religión cristiana, vino a trastornar como consecuencia obligada la filosofía, y de ésta pasó a alterar todos los órdenes de la sociedad civil. A esta fuente hay que remontar el origen de los principios modernos de una libertad desenfrenada, inventados en la gran revolución del siglo pasado y propuestos como base y fundamento de un derecho nuevo, desconocido hasta entonces y contrario en muchas de sus tesis, no solamente al derecho cristiano, sino incluso también al derecho natural ${ }^{24}$.

En PT no queda rastro de esta crítica. Su doctrina política está formulada en términos positivos, no polémicos, subrayando cuáles son sus elementos constituyentes: la autoridad, su necesidad y su sometimiento al orden moral (PT 4651), la democracia como forma de designar a los gobernantes (PT 52), el bien común y las obligaciones de Estado hacia él (PT 53-66), la división de poderes como garantía (PT 68-72), la participación de los ciudadanos en la vida pública (PT 73-74). Hay, como se ve, una sintonía completa entre esta presentación doctrinal y la moderna concepción del Estado. Es cierto que PT subraya más los aspectos morales, sin ignorar las referencias a una visión cristiana de la vida, pero elude el hacer de la Iglesia la garante reconocida del orden político.

GS reproduce esta doctrina, mejorando su estructura y formulación. Premisa fundamental es la afirmación del que el orden político-jurídico tiene como objeto la protección de los derechos de los ciudadanos (GS 73). Define luego lo que caracteriza a la comunidad política como distinta de la sociedad civil

${ }^{23}$ Pietro Pavan había ido elaborando su doctrina política sobre el Estado moderno, que es alternativo a esos dos modelos contrapuestos, en sucesivos textos que sistematizó en 1958 en una de sus obras más conocidas: La democrazia e le sue ragioni. Posteriormente, cf. PAVAN 1988, 71-75, sintetizará lo que es el Estado moderno en estas cuatro notas: Estado de derecho, social, democrático, laico y pluralista.

${ }^{24}$ LEÓN XIII, carta encíclica Immortale Dei, n. 10. Cf. САMACHO 1998, 91-98. 
y ordena mejor sus elementos subordinando explícitamente la función de la autoridad al bien común (GS 74). Aborda a continuación la participación de todos los ciudadanos en la vida pública (GS 75). Especial importancia tiene el número final sobre las relaciones entre la Iglesia y la comunidad política (GS 76), donde aparece inequívocamente la independencia y la autonomía de ambas, partiendo del pluralismo fáctico de nuestras sociedades. Queda claro así que la Iglesia no se identifica con la sociedad, sino que vive en ella y acepta el status que le corresponde a cualquier asociación en su seno. Y ello le permite además rechazar cualquier tipo de privilegios, y sólo reivindicar la libertad necesaria para poder desarrollar su misión.

4) Bases nuevas para una doctrina sobre la guerra. La convicción de que las diferencias entre los pueblos hay que resolverlas, no con el recurso a las armas, sino mediante la negociación y el convenio es uno de los signos de los tiempos señalados al final de capítulos sobre las relaciones entre los Estados (PT 126). Esta convicción tiene que ver con el desarrollo del armamento nuclear:

Esta convicción, hay que confesarlo, nace, en la mayor parte de los casos, de la terrible potencia destructora que los actuales armamentos poseen y del temor a las horribles calamidades y ruinas que tales armamentos acarrearían. Por esto, en nuestra época, que se jacta de poseer la energía atómica, resulta un absurdo sostener que la guerra es un medio apto para resarcir el derecho violado (PT 127).

Esta última afirmación cuestiona la doctrina clásica de la guerra justa, que tradicionalmente se justificaba para resarcir derechos violados, siempre que no existiera otra instancia capaz de hacerlo sin tener que recurrir a las armas. Llama la atención que PT no haga ninguna mención expresa a dicha doctrina, que había sido tratada por tantos moralistas y en tantos documentos oficiales de los papas anteriores.

Cuando PT se publica circula ya en el Concilio un borrador de GS lel que se llamó en ese momento "Schema XVII"), y en él se había seguido la doctrina de Pío XII, el cual no había llegado a un rechazo tan general de la guerra. Las sucesivas redacciones de GS y los debates que se generaron terminaron por asumir la posición de $\mathrm{PT}^{25}$. De este modo GS transcribe literalmente en una nota el texto de PT que acabamos de reproducir para ilustrar la posición del Concilio, que queda formulada así después de mencionar los enormes riesgos de las armas científicas:

Todo esto nos obliga a examinar la guerra con mentalidad totalmente nueva (GS 80).

25 Cf. TuRBANTI 2005, 571-582. Alude también a las discrepancias entre el texto italiano de PT y la versión oficial latina, que suaviza las expresiones. 
Esta "mentalidad totalmente nueva" parece excluir la doctrina de la guerra justa ${ }^{26}$, que había ido endureciéndose a medida que la guerra aumentaba en crueldad como consecuencia de las nuevas estrategias bélicas y las nuevas armas $^{27}$. En los escritos de Pío XII sólo se justificaba ya la guerra estrictamente defensiva. Aunque el rechazo moral de toda acción bélica tampoco se recoge en GS, sí hay una condena solemne de la "guerra total". Es la única condena de un concilio, que sabemos había excluido por principio toda condena siguiendo las orientaciones ya citadas de Juan XXIII. Sin embargo la llamada "guerra total", la que pone como objetivo bélico las poblaciones civiles, queda así condenada:

Teniendo esto es cuenta, este Concilio, haciendo suyas las condenaciones de la guerra total expresadas por los últimos Sumos Pontífices, declara: Toda acción bélica que tienda indiscriminadamente a la destrucción de ciudades enteras o de extensas regiones junto con sus habitantes, es un crimen contra Dios y la humanidad que hay que condenar con firmeza y sin vacilaciones (GS 80).

El texto es inequívoco y su contundencia destaca en contraste con los debates que se produjeron entre los padres conciliares a propósito de la carrera armamentista y la estrategia de disuasión, que fue uno de los momentos álgidos en la cuarta sesión ${ }^{28}$.

5) La necesidad de una autoridad mundial. Si en el tema de la guerra el Concilio avanzó sobre la postura de PT, no ocurrió lo mismo con la propuesta de Juan XXIII de una autoridad mundial que velara por el bien común universal. PT establece un paralelismo fuerte entre el orden político de un país y el de la comunidad internacional: si allí la tutela del bien común exige una autoridad política a su servicio, la creciente interdependencia de la sociedad mundial permite hablar ya de bien común universal, el cual postula una autoridad con competencia en ese nivel supraestatal sobre todos los pueblos de la tierra. Se detallan también algunas de las características de esta autoridad insistiendo sobre todo en el principio de subsidiaridad y sin ocultar los peligros que una instancia de este rango podría acarrear (PT 130-141).

${ }^{26}$ DUBARLE 1970, 713: Discretamente, pero de manera consciente, [el Concilio] abandona la concepción clásica de la guerra justa. Había habido numerosos obispos que lo habían pedido expresamente durante los debates conciliares.

27 Para una visión histórica de conjunto, véase JOBLN 1990, reducido y actualizado en JOBLIN 2012; cf. también VIDAL 2007.

${ }^{28}$ ROUTHIER (2008), 167-170. 
La constitución GS es mucho más cauta en este punto. Se reconoce la mayor interdependencia entre todos los pueblos y se habla del bien común universal, pero sólo se alude a un ordenamiento que garantice el progreso de todos y a las instituciones internacionales ya existentes (GS 84). Se propone además la necesidad de mayor cooperación y coordinación (GS 83, 85). Este silencio respecto a la propuesta reciente de una autoridad mundial, hecha por Juan XXIII, puede entenderse desde las reservas que ya suscitó la propuesta de PT, que se veía como demasiado idealista ${ }^{29}$.

6) El papel de los cristianos, su colaboración con otros y las consecuencias de todo esto para la concepción de la sociedad y las relaciones de ésta con la lglesia. Nos referimos ahora al capítulo $5^{\circ}$ y último, que tiene por título en la versión italiana "Richiami pastorali" (traducido al castellano por "Normas para la acción temporal de cristiano"). Este capítulo fue el que más agradó a Juan XXIII cuando leyó el primer borrador que le fue presentado ${ }^{30}$.

Esta actitud favorable del papa contrasta con las reservas que suscitó. Ya el P. Jarlot al revisar el texto, y dentro de su preocupación por la continuidad con el magisterio anterior, puso de manifiesto que hablar de colaboración de los cristianos con los que no lo son implicaba una forma novedosa de entender el compromiso de los católicos en la construcción de la ciudad temporal. Y se refería a Pío X, el cual insistió en el deber de desplegar con valentía la bandera católica y en la necesidad de unirse los católicos entre sí. Reconoce, sin embargo, Jarlot que las circunstancias han cambiado y que en los trabajos conciliares se está trabajando en esta línea ${ }^{31}$.

Efectivamente el cambio es importante, y pretendido. Supone una nueva forma de situarse ante la sociedad moderna reconociendo en ella su pluralismo ya irreversible que tiene que ver con la secularización creciente. PT se refiere a ella cuando, junto al enorme progreso científico-técnico de nuestra época, constata cómo en las instituciones civiles hay síntomas de un debilitamiento del estímulo

${ }^{29}$ Georges Jarlot había propuesto lisa y llanamente la supresión del capítulo $4^{\circ}$ de PT completo. Lo consideraba "utopique et non fondé en raison". Cf. MELLONI (2010), 114-115.

${ }^{30}$ Ho poiconsacrato tutto il Vespero, circa tre ore nella lettura della encíclica di Pasqua in preparazione, fattami da Mgr. Pavan: "La pace fra gli uomini nell'ordine stabilito da Dio e cioè: nella verità, nella giustizia, nell'amore, nella libertà". Manoscritto di 111 pagine dattilografate. Ho letto tutto, solo, con calma e minutissimamente: e lo trovo lavoro assai bene congegnato e ben fatto. L'ultima parte poi:

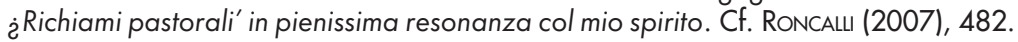

${ }^{31}$ Cf. Melloni (2010), 115-116. Se refiere Jarlot a la Comisión preparatoria de apostolado social. 
y de la inspiración cristiana (PT 151). Y es a la hora de aplicar los principios de la sana doctrina a este nuevo mundo cuando se plantea la colaboración de los católicos con los que no lo son. Después de recordar la recomendación de $M M$ de tener un espíritu de comprensión para las opiniones ajenas y de colaboración en obras en sí buenas o que puedan conducir al bien (MM 239, citado en PT 157), se formula ese doble criterio:

- Distinguir entre el error y quien lo profesa (PT 158). Es un criterio que contrasta abiertamente con la postura mantenida en el magisterio desde el siglo XIX de que solo la verdad tiene derechos ${ }^{32}$.

- Distinguir entre flosofías y corrientes históricas (PT 159): éstas son adaptables a las circunstancias, cosa que no ocurre con las teorías filosóficas que le sirven de inspiración.

Pero estos dos criterios van más allá de su estricto contenido. Suponen situarse en una perspectiva nueva: la de aceptar que en la sociedad moderna, que no es religiosamente confesional, a la Iglesia le corresponde un lugar diferente al que se le reconocía en la sociedad tradicional cristiana. Éste es el punto de partida, ya no discutido, del Concilio, como tendremos ocasión de comprobar de inmediato.

\subsection{Una nueva relación de la Iglesia con la sociedad moderna}

Pietro Pavan cree que el pontificado de Juan XXIII constituye un giro histórico. Y el giro consiste en concebir las relaciones humanas en todos los ámbitos partiendo de lo que se posee en común, y no de aquello en que unos se distinguen de otros. Este enfoque le sirvió también para reenfocar las relaciones de la lglesia con la sociedad. El eco de todo esto se percibe en PT: el papa no quiso exponer directamente la doctrina de la Iglesia; prefirió partir de la constatación de esa conciencia que la humanidad toda ha adquirido de la dignidad de la persona ${ }^{33}$. El mismo Pavan, redactor principal del texto; estaba convencido de que la lglesia debía

32 ZIZOLA 1975, 40, da una gran importancia a esta distinción por las puertas que abre en cuanto a las relaciones de los católicos con los que no lo son: la considera la página fundamental de la encíclica y afirma que había sido escrita personalmente por el papa. Pero este dato no parece concordar con el texto del borrador entregado por Pavan al papa, que reproduce MELLONI 2010, 206.

33 Cf. PaVAn 1984, 111-112. Para Pietro Pavan, la creciente conciencia de la dignidad humana y de sus derechos, así como de su pertenencia a la única familia humana, es el dato más sobresaliente de la época moderna. Cf. BiffI 1990, 17-30. 
situarse de una forma inédita en medio de la comunidad humana: la idea de que la sociedad coincide con la lglesia resulta ya obsoleta, y eso le permite abrirse a la imagen de la Iglesia como fermento, o como sacramento, que terminará por imponerse en la eclesiología del Concilio ${ }^{34}$.

Esta nueva forma de enfocar la relación de la lglesia con la sociedad moderna queda de algún modo reflejada en el capítulo final de ambas encíclicas: el capítulo $4^{\circ}$ de MM ("Las relaciones de convivencia y la aportación de la Iglesia") y el ya mencionado capítulo $5^{\circ}$ de PT ("Normas para la acción temporal del cristiano", "Richiami pastorale" en el italiano). A primera vista ambos capítulos parecen de menor importancia, casi como una conclusión tras los desarrollos doctrinales de una y otra encíclica. Pero el alcance de las ideas contenidas en estas páginas procede de la preocupación que sentía Juan XXIII por abrir vías de colaboración a los católicos con quienes no lo eran. Esta preocupación chocaba de algún modo con las reservas de tantos en la lglesia frente al comunismo en general y frente a la izquierda (comunista o socialista), una inquietud muy viva en Italia en años en que la izquierda estaba en claro ascenso.

Pues bien, todo lo que queda recogido en esos dos capítulos puede verse como en el sustrato de una nueva postura del Vaticano II que se refleja en GS: la Iglesia deja de ocupar un lugar privilegiado en la sociedad plural, que todos debieran reconocer a priori; ahora es una comunidad religiosa dentro de otra comunidad más amplia, la de toda la sociedad; y en su seno los miembros de una y de otra se relacionan en términos de igualdad. Por tanto, ya no es la autoridad doctrinal la que ocupa el primer plano, sino el contacto múltiple de los cristianos con sus conciudadanos; ya no son las relaciones Iglesia-Estado al estilo tradicional, sino las relaciones entre Iglesia como comunidad cristiana y sociedad general como comunidad humana (relaciones entre personas, creyentes o no creyentes).

En GS este enfoque está muy presente en el capítulo $4^{\circ}$ de la Parte I ("Misión de la Iglesia en el mundo contemporáneo"); pero también en una cuestión concreta que se trata en el capítulo anterior a éste: la autonomía de las realidades temporales.

El citado capítulo $4^{\circ}$ es muy representativo de una eclesiología que explicita aquellas intuiciones implícitas en PT: la Iglesia no está frente al mundo, tampoco es el mundo sin más, sino que está en el mundo. Es la comunidad fundada por Jesús

\footnotetext{
34 Toso 2013, 704, considera que ésta es una de las grandes aportaciones de Pavan al pensamiento social de la Iglesia, que deja su huella en las dos encíclicas de Juan XXIII y en documentos conciliares tan importantes como GS y la declaración sobre la libertad religiosa (Dignitatis humanae).
} 
como depositaria del Evangelio y con la misión de anunciarlo. Congar subraya cómo GS, en consonancia con la constitución Lumen gentium, cambia radicalmente la forma de relacionar lo espiritual y lo temporal que habíamos heredado de la Edad Media y que todavía inspiraba el primer borrador sobre la Iglesia elaborado por la Comisión teológica preparatoria del Concilio. Lo espiritual y lo temporal se entendían en términos jurídicos y políticos como dos poderes, pero también como dos niveles de la realidad sobre los que dichos poderes actúan, de forma que la subordinación de lo temporal a lo espiritual justificaba el dominio de los clérigos sobre el resto de la sociedad. Pero Vaticano Il ha vuelto definitivamente la página de la Edad Media ${ }^{35}$. La Iglesia es, no una instancia de autoridad que representa lo espiritual, sino una comunidad, el Pueblo de Dios, no separado del mundo, sino viviendo en medio de él, viviendo y actuando con él. Ya no se trata de relaciones de autoridad a autoridad, de estructura a estructura, sino de relaciones entre la fe y la historia, entre el Evangelio y la civilización. Decir entonces, como se afirma en ese capítulo 4, que la Iglesia ayuda a la persona y a la sociedad y, a la vez, que recibe ayuda del mundo de hoy resulta fácil de comprender.

Con esto conecta el tema de la autonomía de las realidades temporales. GS habla de "justa autonomía" y, para concretar a qué se refiere, distingue una autonomía que sería no solo correcta sino querida por Dios de una autonomía que no se podría aceptar (GS 36). Se parte del temor de muchos contemporáneos a una excesivamente estrecha vinculación entre actividad humana y religión, que limitara la autonomía del hombre, de la sociedad y de la ciencia. Y se reconoce, citando en nota el caso Galileo, que algunos cristianos no entendieron adecuadamente esta autonomía. Todo ello se explica desde la historia de una sociedad identificada con la Iglesia, donde la autoridad de ésta ha controlado el desarrollo del pensamiento y del saber científico. El Concilio reacciona ante este pasado reconociendo que las realidades temporales ("las cosas creadas y la sociedad misma") tienen sus propias leyes que el ser humano debe descubrir, emplear y ordenar, aunque sin olvidar que todo, en última instancia, procede de Dios y está subordinado a sus designios. Lo que falta, en cambio, en este pasaje es la referencia a la autoridad de la Iglesia, que siempre fue tenida como la intérprete autorizada ante la sociedad de este designio de Dios. Tal enfoque, inédito, está en coherencia con ese nuevo lugar que el Vaticano II ha aceptado para la Iglesia en la sociedad moderna. El tema de la "justa autonomía de la realidad terrenal" no es, pues, sino una concreción más de esta nueva concepción de la relaciones entre Iglesia y sociedad moderna, que se cuenta entre los avances más trascendentales del Vaticano II.

${ }^{35}$ Congar 1970, 382. 


\section{Gaudium et spes, la mejor expresión de lo que Juan XXIII quiso que fuera el Concilio}

Quizás con esta última parte se va a completar y va a adquirir su verdadero sentido todo lo que precede en estas páginas: la constitución pastoral acabó siendo la mejor concreción del objetivo último que movió a Juan XXIII a poner en marcha el Concilio. Pero esto no estaba claro desde el principio para todos, ni siquiera para los padres y para los peritos conciliares: fue algo que se fue aclarando por la convergencia de distintos aspectos que queremos recoger ahora. Todo ello fue incidiendo en el complicado proceso de elaboración de GS y en su texto final.

\section{I.Tres indicaciones de Juan XXIII que pretendían orientar el proceso}

Desde el primer anuncio de la convocatoria el papa Juan dio pistas sobre cómo y por qué había llegado a esta decisión que muchos consideraron arriesgada o innecesaria. Estas pistas pueden concretarse en tres términos abundantemente repetidos en estos años, cuyo sentido y alcance se fue progresivamente esclareciendo: el aggiornamento, la atención a los signos de los tiempos, un concilio pastora ${ }^{36}$.

La palabra italiana aggiornamento fue popularizada por Juan XXIII con motivo del Concilio que se preparaba. Fue la orientación más precisa, que se fue imponiendo tras unos primeros momentos en que se insistió más en la unión de los cristianos. Consta que el cardenal Roncalli ya venía utilizando la expresión desde sus años

\footnotetext{
${ }^{36}$ Estos tres aspectos suscitaron reservas no sólo en aquellos años sino hasta hoy porque afectan a la interpretación de todo el Concilio. La novedad que este enfoque suponía, en relación incluso con todos los concilios anteriores, ha permitido hablar del Vaticano II como un acontecimiento, que implica algo de ruptura respecto a la tradición anterior (sobre todo, la que se consolida en la edad media). Se abre así un amplio debate en la Iglesia posconciliar sobre la interpretación auténtica del Concilio: unos insisten en el Concilio como acontecimiento (un buen exponente es la obra en cinco volúmenes dirigida por G. Alberigo Historia del Concilio Vaticano II, que hemos citado varias veces), mientras que otros se oponen a dicha lectura para fijarse sobre todo en los textos aprobados y subrayar su continuidad doctrinal con toda la tradición de la lglesia. Exponente de esta segunda corriente es Agostino Marchetto, que ha criticado insistentemente a la Escuela de Bolonia (Alberigo, etc.) acusándola de dejarse llevar de presupuestos ideológicos y de atender más a lo que se discutía en las comisiones que a lo que ocurría en el aula, más a los diarios particulares de los que participaron en el Concilio que a los documentos oficiales emanados del mismo (cf. MARCHETTO 2008, 413-425 y passim). Benedicto $\mathrm{XVI}$, en su discurso navideño a la curia romana de 22 de diciembre de 2005, quiso terciar en este debate oponiendo a la hermenéutica de la discontinuidad la "hermenéutica de la reforma": según él, puede hablarse de un "proceso de novedad en la continuidad", que se manifiesta como discontinuidad y que se explica si se distingue debidamente las situaciones históricas concretas y sus exigencias de los principios que les sirven de base.
} 
como patriarca de Venecia. En esta etapa de madurez de su vida, la necesidad de aggiornamento concreta una larga y rica experiencia eclesial en diferentes países ${ }^{37}$.

La propuesta de aggiornamento fue recibida con grandes expectativas en la sociedad en general y en la Iglesia, lo que explica la popularidad que el término alcanzó. También caló entre los padres conciliares, aunque la marcha del Concilio conoció momentos de resistencia a lo que era una actitud permanente de búsqueda.

Con todo, la palabra aggiornamento resultó ser la vía menos problemática para asumir la necesidad de cambio o de reforma, términos ambos que suscitaban reservas considerables, en especial después de la encíclica de Pío XII Humani generis (1950) sobre los errores modernos. Ese término, que puso en circulación el papa, hay que relacionarlo con otros dos que se emplearon para aludir al cambio necesario: ressourcement (o vuelta a las fuentes) y desarrollo (se entiende que de la doctrina): si el primero busca en el pasado criterios para el presente, el segundo recurre al presente como clave para interpretar y juzgar al pasado. Con estas expresiones se evita la palabra reforma, que todavía algunos relacionaban con la reforma protestante, mientras que otros las vinculaban a cambios en determinadas prácticas de la vida de la Iglesia en ámbitos como la liturgia, el derecho canónico o la pastoral. Lo que estaba en juego detrás del término aggiornamento y los otros emparentados con él era mucho más: quería ser expresión de prontitud y disposición para hacerse presente en un mundo distinto y nuevo ${ }^{38}$.

El camino indicado para esta actualización había de ser la atención a los signos de los tiempos, una expresión cuya presencia en PT ya analizamos. También fue un término que Juan XXIII empleó en relación con la tarea que esperaba al Concilio y, más en general, a la Iglesia toda. En este caso el término llegó a ser objeto de debates enconados en el Concilio mismo, no sólo en torno a su verdadero sentido, sino también en relación con su papel en la elaboración precisamente de GS.

Fue el dominico Marie-Dominique Chenu quien más abogó por hacer de la lectura de los signos de los tiempos el método a seguir en $\mathrm{GS}^{39}$, frente a propuestas

${ }^{37}$ Cf. Alberigo 2008, 512-515.

${ }^{38}$ Cf. O'MAlley, 2012. El mismo año que la encíclica de Pío XIl apareció la conocida obra de J.Y. Congar, Vraie et fausse réforme dans l'Église, traducida como Falsas y verdaderas reformas en la Iglesia, Instituto de Estudios Políticos, Madrid 1953. Son conocidas las dificultades que encontró su autor pocos años después, cuando se le prohibió enseñar y escribir y se le ordenó alejarse de París.

${ }^{39}$ El dominico Marie-Dominique Chenu fue desde sus primeros estudios filosófico-teológicos un entusiasta 
de carácter más doctrinal que procedían de otros ambientes teológicos también centroeuropeos $^{40}$. El debate sirvió para precisar mejor el recurso a los signos de los tiempos. El propio Chenu distinguía un sentido más sociológico de otro más teológico. De acuerdo con el primero, se trataría de hechos significativos que han tenido una influencia decisiva en la evolución del mundo, pero de modo que lo que importa en ellos no es tanto el hecho bruto, cuanto la toma de conciencia que eso ha provocado en la humanidad. Desde un punto de vista teológico, los signos de los tiempos quieren subrayar la conexión entre los acontecimientos del mundo y la presencia de la Iglesia, evitando así que ésta considere los hechos y los problemas del mundo como desde fuera. En palabras de José M. González Ruiz, la Iglesia no viene a crear un mundo de valores propios para ofrecer a los hombres el refugio de su extraterritorialidad salvadora ${ }^{41}$.

El debate permitió clarificar este doble sentido. Según una comprensión más histórico-teológica (que es la que está presente en el texto tan veces invocado de Mt 16,4), la perspectiva es más cristológica y escatológica, con una clara referencia a los tiempos mesiánicos del Reinado de Dios y con una invitación a la Iglesia a discernir en la historia la presencia de Dios que actúa por medio de su Espíritu. Pero hay otra comprensión más sociológica que alude a los síntomas y notas características de cada época, con el fin de que la lglesia pueda responder adecuadamente a ellos. En este sentido se expresó el Concilio en la "Exposición preliminar" de GS ("Situación del hombre en el mundo de hoy"):

Para cumplir esta misión es deber permanente de la lglesia escrutar a fondo los signos de la época e interpretarlos a la luz del Evangelio, de forma que, acomodándose a cada generación, pueda la Iglesia responder a los perennes interrogantes de la humanidad

del método histórico, que aprendió con el exegeta, también dominico, Marie-Joseph Lagrange en Le Saulchoir y luego aplicó a los diferentes campos del saber teológico, convencido que ninguna doctrina puede entenderse ignorando el contexto histórico en que se formuló. Pero ello le costó algunas sanciones de las autoridades vaticanas, la última de las cuales estuvo relacionada con la supresión del movimiento de los sacerdotes obreros en Francia (1954). Aunque no fue perito oficial del Concilio, participó por distintas vías en los debates y en la elaboración de textos. Gracias al P. Congar fue incluido en la subcomisión encargada de estudiar los signos de los tiempos. Su artículo con ese mismo título (CHENU 1965) fue publicado coincidiendo en el tiempo con esos debates conciliares. Cf. CARAM 2012.

40 Este fue uno de los puntos donde se rompió un cierto consenso entre los padres franceses y los alemanes, que tanto marcó la marcha del Concilio en momentos decisivos. Ahora bien, los teólogos alemanes, que apostaban por un enfoque más doctrinal y teológico, tampoco querían verse alineados con los grupos más integristas, que también se oponían a este método, aunque por razones distintas.

${ }^{41}$ El tema puede verse desarrollado en el artículo ya citado: CHENU 1965, donde se recoge la frase citada de González Ruiz, pág. 36. 
sobre el sentido de la vida presente y de la vida futura y sobre la mutua relación de ambas (GS 4).

El sentido más histórico-teológico queda, en cambio, reflejado en la introducción a la Primera Parte de GS:

El Pueblo de Dios, movido por la fe, que le impulsa a creer que quien lo conduce es el Espíritu del Señor, que llena el universo, procura discernir en los acontecimientos, exigencias y deseos, de los cuales participa juntamente con sus contemporáneos, los signos verdaderos de la presencia o de los planes de Dios (GS 11).

Pero en ambos casos se apunta en la misma dirección: que la lglesia no puede quedar encerrada en el pasado ni en lo intemporal de las verdades eternas, sino que tiene que estar abierta al devenir histórico: y no sólo por razones estratégicas, también por motivos teológicos ${ }^{42}$.

Los signos de los tiempos (que ya vimos cómo se atendían en PT) ocupan ahora un lugar muy destacado y marcan una forma novedosa de hacer teología. Pero fue a lo largo de su desarrollo como el Concilio fue comprendiendo en qué consistía eso de interpretar los signos de los tiempos: una experiencia bajo la autoridad única de la Palabra de Dios que se realiza de forma colegiada como expresión del gobierno pastoral $^{43}$.

Un tercer indicador de la voluntad de Juan XXIII sobre el Concilio fue el que éste tuviera un claro talante pastora ${ }^{44}$. También el término escogido por el papa suscitó debates y resistencias. En algún momento fue interpretado en contraposición a doctrinal, despertando seria inquietud en quienes habían asignado al Concilio, por propia convicción o como expresión de una cierta inercia histórica, la función tradicional de corregir errores.

Esta directriz del papa de celebrar un Concilio pastoral apenas fue tenida en cuenta por quienes tuvieron mayores responsabilidades en la elaboración de los documentos en la fase preparatoria. Para los trabajos de esta fase se hizo una distinción nítida entre cuestiones pastorales y cuestiones doctrinales. Esta separa

42 Para un análisis del tema en el Concilio y en la Iglesia posconciliar hasta hoy, cf. MeRINo Beas 2006.

${ }^{43}$ Cf. ThÉOBALD 2012.

${ }^{44}$ CF. Alberigo 2008, 516-519. 
ción subrayaba que el objetivo fundamental del Concilio debía ser la clarificación doctrinal, aunque había muchas cuestiones prácticas que también serían tratadas ${ }^{45}$.

Las dudas sobre qué enfoque debería predominar pueden considerarse como una de las causas que más frenaron la marcha de los trabajos. Y hubo que comenzar casi de nuevo una vez que el Concilio arrancó y los padres fueron comprendiendo y haciendo suya con gusto esta nueva orientación que el papa había querido.

Cuando se habla de enfoque pastoral no hay que contraponerlo a enfoque doctrinal, porque lo pastoral no es sino el criterio primordial utilizado, no ya para decisiones sobre cuestiones prácticas que afectan a la vida de los creyentes, sino para la misma formulación y presentación de la verdad que se quiere comunicar al mundo contemporáneo. La Iglesia está adquiriendo una conciencia nueva de cuál es su misión. Aunque algunos lo utilizaron como síntoma de la debilidad del Concilio, que no había sido capaz de entrar en los temas más trascendentes, o para quitarle autoridad a sus documentos, el término pastoral viene a expresar en el fondo que éste es un concilio distinto de todos los anteriores.

\subsection{La novedad del Concilio y la novedad de Gaudium et spes}

Esta novedad del Concilio, que había quedado formulada programáticamente en el discurso de Juan XXIII en la inauguración solemne, se refleja en GS quizás como en ningún otro documento. Tan conscientes eran los padres de que estaban ante un documento de un género diferente e inédito en los concilios, que todavía en la cuarta sesión del Concilio había una cierta presión para que no se publicara.

Las razones para no publicarlo eran diversas. Ante todo, no se acaba de ver cuál habría de ser el método a emplear en él. Por otra parte, los sucesivos borradores presentados no acababan de convencer: se echaba de menos un contenido teológico más elaborado, por ejemplo en cuestiones tan delicadas como el concepto de mundo, la relación entre natural y sobrenatural, la dimensión escatológica; había un optimismo excesivo que ignoraba la realidad del pecado... Además los problemas que se querían abordar eran excesivamente complejos y no se había previsto la colaboración de expertos que pudieran ayudar: entre estos temas se

\footnotetext{
${ }^{45}$ En la etapa preparatoria se impuso esta distribución de competencias entre comisiones reservándose la comisión teológica todo lo relativo a la doctrina. El estudio detenido de los trabajos de todas las comisiones y las dificultades que surgieron de esta división de competencias está muy documentado en KOMONCHAK 1999.
} 
señalaban una eventual condena del ateísmo y del comunismo, el control de la natalidad, la guerra y la paz, la carrera armamentista. El capítulo sobre la economía era criticado por su sesgo excesivamente occidental. No gustaba el capítulo sobre la cultura, mientras que el de la política había sido improvisado en la última intersesión ya que no figuraba en los borradores anteriores.

No eran pocas ni banales las dificultades. Y a todas ellas se añadía la más determinante: el tiempo. En la tercera sesión ya se planteó la posibilidad de renunciar al que todavía se conocía como el Esquema XIII. Se optó finalmente por continuar una vez que Pablo VI decidió que se celebrara una cuarta sesión. Cuando se anunció que ésta sería ya la última, nuevamente surgió la cuestión. Y ahora ya con carácter irremisible ante la insatisfacción que despertó el texto que se presentó en el aula en septiembre de 1965.

Sin embargo, era más fuerte la conciencia de que este documento era esencial para comprender lo que el Concilio estaba queriendo ser. No era un documento más: renunciar a él significaría un golpe duro para las expectativas de inaugurar una relación nueva de diálogo con el mundo moderno, que Juan XXIII y el mismo desarrollo del Concilio habían despertado.

Se buscaron distintas alternativas. La más radical, como ya hemos dicho, consistía en no publicarlo, y dejar que su temática fuera abordada posteriormente, bien por las distintas conferencias episcopales, bien en un futuro sínodo. De publicarlo, algunos abogaban por hacerlo como una "declaración", fórmula más modesta y de menos pretensiones ${ }^{46}$. Otros cuestionaban llamarlo "constitución", término que el propio Concilio había reservado para cuestiones dogmáticas. Añadir el calificativo de "pastoral" no hacía sino incrementar la ambigüedad inherente al significado de esta palabra, como ya hemos indicado: algunos pensaban incluso que de este modo se era inconsecuente con la distinción que se hacía hasta entonces entre afirmaciones dogmáticas y aplicaciones pastorales.

Terminó imponiéndose la denominación de Constitución pastoral, echando mano de un adjetivo que había querido expresar la novedad del Vaticano II respecto a los concilios anteriores, y que ahora se escogía para calificar el tenor propio de este documento tan representativo de esta novedad ${ }^{47}$.

${ }^{46}$ Eco de este debate en el aula: cf. Cf. Routhier 2008, 139-141.

${ }^{47} \mathrm{Karl}$ Rahner reflexionaría más tarde sobre el sentido de la expresión Constitución pastoral, tan nueva y, para muchos casi contradictoria: Una constitución pastoral es un conjunto de directrices de la 


\subsection{El apoyo de Pablo VI}

Si GS llegó a feliz término fue sin duda gracias al apoyo que le prestó Pablo VI. Este apoyo puede concretarse en una triple coordenada.

La primera fue la encíclica Ecclesiam suam (6 agosto 1964), en la que suele verse como un texto programático del sucesor del Juan XXIII. Su título ya es significativo: Sobre los caminos que la Iglesia católica debe seguir en la actualidad para cumplir su misión.

La encíclica se articula en torno a una triple tarea que concreta esa misión hoy según Pablo Vl: profundizar la conciencia de sí misma, renovarse, abrirse al diálogo con el mundo moderno. La importancia que adquiere el tratamiento del diálogo en ella y las directrices que se dan para lo que ha de ser un auténtico diálogo han hecho que este documento sea considerado como "la encíclica del diálogo". Está fuera de duda que Pablo VI pretendió con su documento reforzar la orientación que Juan XXIII había dado inicialmente al Concilio.

Una segunda coordenada de este apoyo fue la visita de Pablo VI a la ONU y el discurso que pronunció ante su asamblea general (5 octubre 1965). Coincidió con los días en que se discutía en el aula el texto de GS. Su presencia en aquel foro mundial era la mejor expresión del deseo de la Iglesia de abrirse al diálogo con el mundo y de trabajar por la paz. El papa iba como mensajero del Concilio universal a ofrecer su colaboración a una institución también de dimensiones universales, a la que reconocía el servicio que estaba prestando a la humanidad ${ }^{48}$.

Iglesia, válidas ante todo para sus propios miembros, pero también, en cierta manera, para todos los hombres dispuestos a prestar oído a su voz. Y estas directrices, elaboradas como consecuencia de un análisis de la situación presente, en la que entra algo de carismático, se presentan como decisiones de la Iglesia en respuesta a la llamada carismática de Dios. (RAHNER 1968, 36). Él habla de "directrices" por contraposición a lo estrictamente "doctrinal": carecen del rigor de la doctrina, y por consiguiente no admiten una verdadera demostración; son, más bien, llamadas dirigidas a los cristianos de hoy con vistas a ciertos compromisos de alcance histórico (ibid., 40-41).

${ }^{48}$ Cuando Pablo VI se dirigió a los padres conciliares después de aterrizar de vuelta en Roma, estos decidieron por unanimidad que su discurso en Nueva York fuera incluido en las actas del Concilio como dejando constancia que en él se había hecho realidad el objetivo último de la asamblea. Incluso algunos llegaron a proponer que el discurso sustituyera al documento que estaba en discusión, que era la constitución Gaudium et spes. Cf. HünERMANN 2008, 355-357. 
Por último Pablo VI prestó un apoyo incalculable para que GS llegara a buen puerto con su seguimiento continuo a través de los que presidían las comisiones encargadas de la redacción, especialmente con Mons. Garrone. Ello es muestra de que consideraba el futuro texto como uno de los objetivos más importantes del Concilio ${ }^{49}$.

\subsection{Las dialécticas de fondo}

La novedad de GS como herencia de la impronta de Juan XXIII al Concilio y a la Iglesia que salió de él se comprende mejor si se tienen en cuenta ciertas tensiones subyacentes. En el fondo pueden considerarse manifestación del pluralismo que siempre ha existido en la Iglesia. Pero en estos momentos expresan también un cambio de rumbo que abre paso a una nueva actitud ante el mundo.

Una primera tensión tiene que ver con la actitud ante el mundo, ante la creación y las realidades terrenas. Unos tienen una actitud positiva y optimista, que se fija más en lo que se da en él de progreso y de desarrollo, actitud que en algunos momentos marcó tanto el texto que justificó el que se tachara de ingenuamente optimista. Otros lo ven como una realidad negativa. El cardenal Ruffini lo describía así en una de sus intervenciones en el aula:

(...) una confusa masa de pecados y delitos que está corrompiendo a gran parte de la sociedad, especialmente en los países que se jactan de poseer una civilización humana sumamente refinada (...); moralidades bajas, hostiles incluso a la ley natural, se están difundiendo más y más a diario, porque los medios de corrupción se están incrementando incesantemente (ASIV/2, 21).

Estas dos lecturas del mundo apelaban también a la autoridad de la lglesia. Y, a decir verdad, ambas encontraban donde apoyarse: si la primera se reflejaba mejor en Juan XXIII, la otra podía estar más en sintonía con muchos textos de Pío XII.

En algún momento el problema se quiso relacionar con el concepto bíblico del mundo (sobre todo en la teología joannea), que se consideraba demasiado ausente en los sucesivos borradores de GS. Sin embargo, el método escogido para este documento no pedía tanto una teología del mundo (para lo que hubiera sido necesaria alguna referencia al menos a la teología de Juan), sino una lectura del mundo de hoy a partir de los signos de los tiempos.

${ }^{49}$ Cf. HünermanN 2008, 339-340. 
Relacionada con esta dialéctica de dos actitudes ante la realidad de este mundo puede considerarse también la contraposición de dos eclesiologías. Para algunos el mundo es esencialmente malo, está poseído por el demonio, constituye una amenaza: para éstos la lglesia representa una fortaleza. Esa lglesia se identifica más con la Jerusalén celestial que ha descendido ya a la tierra. Frente a esa vivencia de la lglesia aparece otra que subraya más su realidad histórica, la condición peregrina del pueblo de Dios. Esta lglesia no se aferra a esas certezas en las que podría haber encontrado seguridad en la época moderna y contemporánea como reacción contra los traumas que le produjo primeramente la Reforma protestante y luego la Revolución francesa.

De nuevo el cardenal Ruffini expresa bien cómo concebía el Concilio desde su visión de la lglesia como fortaleza y fuente de seguridad:

El próximo concilio -si lo cree oportuno- podrá dotar a sus principales enseñanzas [de los últimos papas] de aquel valor definitivo que los situaría fuera y por encima de toda discusión ${ }^{50}$.

El Concilio no siguió esta senda, que había sugerido el cardenal Ruffini pocos meses después del primer anuncio hecho por Juan XXIII. Pero no faltaron los que se aferraban a esta idea y no acababan de entender el nuevo giro que la mayoría quería imprimir a sus trabajos. En todo caso, hay una estrecha relación entre la concepción de la lglesia y la concepción de las relaciones de la lglesia con el mundo. El Concilio rechazó pronto la idea dominante en la teología que inspiró los textos elaborados en la etapa preparatoria tan marcados por la polémica antimoderna: en ese marco, la función de la Iglesia (o mejor, del magisterio eclesiástico) era la de conservar el depósito de la fe. A lo largo del Concilio se fue imponiendo una visión distinta de la lglesia que incorporó nuevos elementos: la misión de evangelizar (gracias a la teología francesa y, sobre todo, a Congar), la contribución a la tarea construir la ciudad terrena, el sentido de servicio a la humanidad, la apertura al

${ }^{50}$ En un discurso en la Universidad Lateranense el 28 de octubre de 1959, el cardenal Ruffini recordaba cómo ya le había sugerido al mismo Pío XII la conveniencia de convocar un concilio:

Los profundos cambios sociales, derivados de los progresos de la técnica y de la expansión de la civilización, el acentuado espíritu de crítica que lleva a revisar y en parte a socavar las tradiciones antiguas, las nuevas formas de contradecir a las verdades reveladas, la desbordada autonomía de pensamiento y de acción de las personas individuales y asociadas frente a las leyes de la moral hasta ayer fuera de discusión con la consiguiente confusión de ideas en muchos que incluso se llaman católicos, hacía sentir a las personas rectas desde hace algún tiempo la necesidad de decisiones y orientaciones seguras. Se deseaba por tanto que al menos algunos principios fuesen sancionados por la máxima autoridad y quedase prácticamente reforzada su validez mediante el sufragio del episcopado. Que, junto con el papa, y bajo su suprema jurisdicción, constituye el magisterio de la iglesia, la lglesia docente. Cf. Ruffini 1960. 
diálogo (aquí fue decisivo el impulso de Pablo VI). En la fase final este enfoque eclesiológico se complementó con una insistencia en lo cristológico (teología de la encarnación), que subraya cómo la humanidad entera participa en una historia común y está destinada toda ella a la salvación: la lglesia es solidaria de toda la humanidad, y en su seno está llamada a descubrir los signos de los tiempos ${ }^{51}$.

\section{A modo de conclusión: Gaudium et spes como punto de partida, no como término}

Lo había dicho Mons. Garrone en el aula al terminar el debate sobre el texto presentado en septiembre-octubre de 1965: reconocía que las críticas habían sido duras, pero ello era sólo expresión de que la labor estaba incompleta porque los temas revestía una extraordinaria dificultad y era la primera vez que un concilio trataba de entrar en diálogo, de manera totalmente nueva, con el mundo ${ }^{52}$.

En este sentido era difícil que se llegara a un texto final que dejara satisfechos a todos. Sin embargo, el miedo a que los resultados no fueran los deseados, que llevó a que algunos propusieran renunciar a un documento de este estilo y remitir los temas que se pretendían tratar en él al magisterio ordinario de la lglesia, no fue suficiente para que el Concilio renunciara a explorar esta vía inédita. El texto de GS no va a ser un texto definitivo ni el término final de un camino, sino sólo un punto de partida, o la primera etapa de un camino que se inaugura.

Así lo reconoce también de algún modo Pablo VI en su alocución del 7 diciembre 1965 durante la última sesión pública tras la aprobación de GS, un texto donde encontramos resumidas las claves de lo que ha sido el Concilio. Reconoce que han sido múltiples las cuestiones relativas al bienestar humano que han sido tratadas y no con la amplitud deseada: por eso muchas quedan reservadas para estudios ulteriores porque son susceptibles de mayor profundización y de nuevas aplicaciones.

Pero no hay duda que Juan XXIII está en el punto de partida de este largo proceso, que al final de Concilio se consideraba sólo como la primera etapa de un nuevo camino que se abría. Hemos querido mostrarlo desde el anuncio del Concilio y las primeras orientaciones que dio en el momento inaugural, desde sus dos grandes

\footnotetext{
${ }^{51}$ Cf. TuRBanti 2000, 802-809.

52 Tomamos la referencia de HüNERMANN 2008, 351.
} 
documentos sociales, desde sus profundas intuiciones que llevaron revisar la visión del mundo y del lugar que la Iglesia ocupa en él.

GS fue un hito en ese camino, un hito que estuvo a punto de no hacerse realidad. Hoy nos alegramos de que, a pesar de sus limitaciones, siga marcando un punto de inflexión y siga constituyendo un estímulo de renovación para la lglesia 50 años después.

\section{Bibliografía}

Alberigo, G. (1981) "Del bastone alla misericordia. II magistero nel cattolicesimo contemporaneo", Cristianesimo nella Storia 2, 487-521.

Alberigo, G. (2008), "La transición hacia una nueva era", en G. Alberigo (dir.), Historia del Concilio Vaticano II. Vol. V: Un concilio de transición. El cuarto periodo y la conclusión del Concilio (septiembre-diciembre 1965), Salamanca, Sígueme, 509-569.

BIFFI, F. (1990), Il cantico dell'uomo. Introduzione al pensiero sociale del card. Pietro Pavan, Roma, Città Nuova.

Calvez, J.-Y. (1962), "La socialisation dans la pensée de l'Église", Revue de l'Action Populaire n. 158, 517-528.

Camacho, I. ( $\left.{ }^{3} 1998\right)$, Doctrina Social de la Iglesia. Una aproximación histórica, Madrid, San Pablo.

CaMACHO, I. (2014) "Propiedad", en J. Sols LuCIA(ed.), Pensamiento social cristiano abierto al siglo XXI. A partir de la encíclica Caritas in veritate, Santander, Sal Terrae, 223-257.

Caram, M. J. (2012), "Marie Dominique Chenu. Un teólogo en la historia", Anatéllei n. 28, 121-133.

Chenu, M.-D. (1965), "Les signes des temps", Nouvelle Revue Théologique 87, 29-39.

Congar, Y. (1950) Vraie et fausse réforme dans l'Église, Paris, Cerf (en castellano, con el título Falsas y verdaderas reformas en la Iglesia, Madrid, Instituto de Estudios Políticos, 1953, nueva edición con el título Verdadera y falsa reforma de la Iglesia, Salamanca 2014, Sígueme). 
Congar, Y. (1970), "El papel de la lglesia en el mundo de hoy $\left(1^{a}\right.$ parte, capítulo IV)", en: Y. Congar - M. Peuchmaurd (dir.), La Iglesia en el mundo de hoy. Constitución pastoral "Gaudium et spes" - Tomo II: Comentarios, Madrid, Taurus, 373-403.

Congar, Y. (2002), Mon Journal du Concile I, Paris, Cerf.

DUBARLE, D. (1970), "La salvaguarda de la paz y la construcción de la comunidad de naciones", en: Y. Congar - M. PeuChmaurd (dir.), La lglesia en el mundo de hoy. Constitución pastoral "Gaudium et spes" - Tomo II: Comentarios, Madrid, Taurus, 705-779.

Hebblethwalte, P. (1983) "Le discours de Jean XXIII à l'ouverture de Vatican II", Recherche de Science Religieuse 71, 203-212.

HebblethwaIte, P. (2000), Juan XXIII, el papa del Concilio, Madrid, PPC.

HünermanN, P. (2008), "Las semanas finales del Concilio", en: G. Alberigo (dir.), Historia del Concilio Vaticano II. Vol. V: Un concilio de transición. El cuarto periodo y la conclusión del Concilio (septiembre-diciembre 1965), Leuven, Peeters / Salamanca, Sígueme, 331-434.

JOBLIN, J. (1990), La Iglesia y la guerra. Conciencia, violencia y poder, Barcelona, Herder.

JoвıIN, J. (2012), "Elements pour une réflexion sur la théorie de la guerre juste", Gregorianum 93, 809-829.

JUAN XXIII (2007), Pater amabilis. Agende del pontefice, 1958-1963. Edizioni critica e annotazione a cura di Mauro Velati, Bolonia, Istituto per le Scienze Religiose.

KomonchaK, J. (1999), "La lucha por el Concilio durante la preparación", en: G. AlberIGo (dir.), Historia del Concilio Vaticano II. Vol. I: El catolicismo hacia una nueva era. El anuncio y la preparación, Salamanca, Sígueme, 166-280.

Marchetto, A. (2008), El Concilio Ecuménico Vaticano II. Contrapunto para su historia, Valencia, Edicep.

MelONI, A. (1996), "Il contesto e il significato storico della Pacem in terris", en: A. CavAGnA (ed.), I cristiani e la pace. Rivivendo la "Pacem in terris", Bolonia, Dehoniane, 21-35.

MELONI, A. (2010), Pacem interris. Storia dell'ultima enciclica di Papa Giovanni, Bari, Laterza.

Merino BeAs, P. (2006) "La categoría teológica 'signos de los tiempos': usos e implicancias en el Magisterio y en la teología católica": Anales de Teología 8, 65-167. 
O'Malley, J. W. (2012), "Ressourcement y reforma en el Vaticano II": Concilium $48,361-371$.

PaVAN, P. (1958), La democrazia e le sue ragioni. Studio introduttivo di Mario Toso, Roma, Studium 2003.

Pavan, P. (1984), "Il momento storico di Giovanni XXIII e della Pacem in terris: sua incidenza negli atti conciliari e nella vita della Chiesa e sua influenza nella società contemporanea", en P. PAVAN (1992), Scritti - IV: La Chiesa luce e fermento dell'umanità, Roma, Città Nuova, 106-112.

Pavan, P. (1988), "Acuta e stimolante rilettura dell'enciclica 'Pacem in terris'. A veinticinque anni dalla sua pubblicazione", en P. PaVAN (1992), Scritti - IV, I. c., 52-105.

RAHNER, K. (1968), "Reflexiones sobre la problemática de una Constitución pastoral", en: La Iglesia en el mundo actual. Constitución "Gaudium et spes". Comentarios al Esquema XIII, Bilbao, Desclée de Brouwer, 17-43.

Routhier, G. (2008), "Finalizar la obra comenzada. La experiencia del cuarto periodo, una experiencia que ponía a prueba", en: G. AlberIGo (dir.), Historia del Concilio Vaticano II. Vol. V: Un concilio de transición. El cuarto periodo y la conclusión del Concilio (septiembre-diciembre 1965), Salamanca, Sígueme, 59-177.

RufFINI, E. (1960), "Il Santo Padre Giovanni XXIII nel primo anno di pontificato": Divinitas 4, 7-27.

SORGE, B. (1963), "Socializzazionee socialismo", Civiltà Cattolica, vol. 1 14/1, 326-337.

SOUSBERGHE, L. (1960), "Propriété de 'droit naturel'. Thèse néo-scolastique et tradition scolastique", Nouvelle Revue Théologique 72, 581-600.

ThÉOBALD, C. (2012), "El Concilio Vaticano Il frente a lo desconocido. La aventura de un discernimiento colegiado de los signos de los tiempos": Concilium 48, 373-382.

Toso, M. (2013), "Il cardinale Pietro Pavan: Protagonista del Concilio Vaticano II e della rinascita del pensiero sociale cristiano. Profezia e testimonianza", Lateranum 79, 701-722.

TURBANTI, G. (2000), Un concilio per il mondo moderno. La redazione della costituzione pastorale "Gaudium et spes" del Vaticano II, Bolonia, II Mulino.

TuRbanti, G. (2005), "Il tema della guerra al concilio Vaticano II", en: M. FranzINeLL - R. Bottoni (eds.), Chiesa e guerra. Dalla benedizione delle armi alla "Pacem in 
terris", Bolonia, II Mulino, 563-606.

VIDAL, M. (2007), "Hacia el cambio de paradigma en la moral de la respuesta a los conflictos interestatales y mundiales": Moralia 30, 79-111.

VILLAIN, J. (1961), "L'Encyclique Mater et magistra. L'Église et les problèmes sociaux": Informations Catholiques Internationales, 151, 17-31.

Zızola, G. (1975) La utopía del papa Juan, Salamanca, Sígueme. 